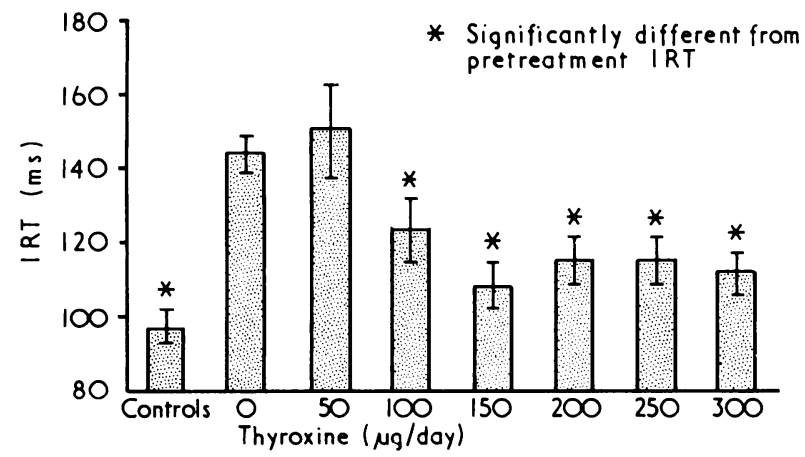

FIG 3-Mean isolvolumetric relaxation times ( $t$ SE of mean) in nine patients with hypothyroidism who progressed to dose of $300 \mu \mathrm{g} /$ day during trial.

Benchimol and Dimond et al in their study of the apex cardiogram in ischaemic heart disease made no reference to abnormalities of the IRT.11

Our results show that the IRT is prolonged in hypothyroid patients and reverts to normal after thyroxine replacement treatment. Since there was no radiographic or clinical evidence of pericardial effusion in any of our patients, we may have been measuring the effect of myxoedematous infiltration of the muscle fibres (a finding first reported in $1880^{12}$ ), and possibly this infiltration no longer causes detectable change in the IRT when the patient is rendered euthyroid.

It is particularly interesting that there was no reduction in the IRT when the dose of thyroxine was increased above $150 \mu \mathrm{g} / \mathrm{day}$, as this finding correlates well with work showing that most hypothyroid patients became euthyroid, using the serum thyrotrophin level as a criterion, on 100-200 $\mu \mathrm{g}$ /day of thyroxine and may be hyperthyroid when on the accepted full replacement regimen of $300 \mu \mathrm{g}$ !day of thyroxine. ${ }^{13}$

There is at present no readily available clinical or biochemical test that indicates the gradual return to normal body metabolism with increasing doses of thyroxine and, in particular, none that show normal end-organ function on less than the full replacement dose of $300 \mu \mathrm{g} /$ day. The IRT as an index of end-organ function in hypothyroidism therefore seems to have great potential as both a research and a diagnostic tool in thyroid disease.

We are grateful to the department of cardiology for their technical help and for use of their equipment.

Requests for reprints should be addressed to Dr A M M Shepherd, Department of Pharmacology and Therapeutics, The University, Dundee, Scotland.

\section{References}

${ }^{1}$ Benchimol, A, and Dimond, E G, American fournal of Cardiology, 1963, $12,368$.

2 Benchimol, A, Dimond, E G, and Carson, J C, American Heart fournal, 1961, 61, 485

${ }^{3}$ Legler, J F, Benchimol, A, and Dimond, E G, British Heart fournal, 1963, 25, 246.

${ }^{4}$ Nuki, G, and Bayliss, R I S, Postgraduate Medical fournal, 1968, 44, 97

5 Coulshed, N, and Epstein, E J, British Heart Fournal, 1963, 25, 697.

${ }^{6}$ Benchimol, A, and Ellis, J G, American fournal of Cardiology, 1967, 19, 196.

${ }^{7}$ Billewicz, W Z, et al, Quarterly fournal of Medicine, 1969, 38, 255.

8 Simpson, G M, Blair, J H, and Nartowicz, G R, New York State fournal of Medicine, 1963, 63, 1148

9 Jezek, V, Sbornik Lekarsky, 1961, 63, 313.

10 Harrison, T R, et al, American Heart fournal, 1964, 67, 189.

11 Benchimol, A, and Dimond, E G, British Heart fournal, 1962, 24, 581.

12 Ord, W M, Transactions of the Clinical Society of London, 1880, 13, 15.

13 Evered, D, et al, British Medical fournal, 1973, 3, 131.

\title{
Relation between blood pressure, weight, and plasma sugar and serum insulin levels in schoolchildren aged 9-12 years in Westland, Holland
}

\author{
C DU V FLOREY, S UPPAL，C LOWY
}

British Medical fournal, 1976, 1, 1368-1371

\section{Summary}

In 2388 schoolchildren aged 9-12 years who took part in a study of cardiovascular risk factors in Westland, Holland, plasma sugar concentrations were found to be positively correlated with systolic and diastolic blood pressure, independently of weight. Serum cholesterol levels were also related to systolic blood pressure in boys, but much less strongly than plasma sugar levels. The relation between serum insulin and blood pressure, independent of plasma sugar, was weak. The relation between plasma

St Thomas's Hospital Medical School, London SE1

C du V FLOREY, MD, senior lecturer, department of community medicine C LOWY, MRCP, senior lecturer, department of chemical pathology

Department of Cardiology, University Hospital, Leiden, the Netherlands

S UPPAL, MD, consultant cardiologist sugar and systolic pressure existed for both sexes and regardless of whether measurements were made in the morning or afternoon; its association with diastolic pressure was weaker, and was not so consistent over all groups. These findings suggest that the relations between risk factors for coronary heart disease that exist in adults are already evident in childhood.

\section{Introduction}

The epidemiology of coronary heart disease (CHD) has been studied extensively in adults. People with raised serum cholesterol levels, blood pressure, and probably body weight are more likely than those with normal levels to have evidence of myocardial ischaemia at the time of the measurement or to suffer overt clinical CHD in the future. Raised blood sugar concentrations (measured after an oral glucose challenge) have also been strongly suggested as a risk factor for CHD but have attracted far less attention than the factors already mentioned.

Reasons for considering raised blood sugar as a precursor of CHD have been well reviewed by Epstein. ${ }^{1}$ Necropsy, clinical, and laboratory studies over the past 50 years have mostly 
indicated that atherosclerotic changes are more common or more severe among diabetics than among non-diabetics. ${ }^{12}$ Blood pressure in adults has been shown to be related to one-hour post-challenge blood sugar levels, independently of the effects of body bulk and age. ${ }^{3-7}$ From this it has been postulated that part of the link between blood sugar levels and CHD might be indirect, through the effect of the former on blood pressure.

Our aim was to investigate the pattern of risk factors for CHD in schoolchildren aged 9-12 years. Some of the data have already been published. ${ }^{8}$ In this paper we describe the association between blood pressure, plasma sugar, and serum insulin measured one hour after an oral challenge of glucose.

\section{Subjects and methods}

The study population, described elsewhere, ${ }^{89}$ consisted of 2388 children aged 9-12 years in the fourth and fifth classes of all 41 schools in the Westland district near Rotterdam, Holland. They represented $96.3 \%$ of the target population.

Systolic and diastolic V (disappearance of sounds) pressures were measured by nine observers using two random-zero sphygmomanometers (Hawksley). The observers were trained in taking blood pressures with a special film and tapes produced in the UK. ${ }^{8}$ The largest of three cuffs $(7.5,10,12.5 \mathrm{~cm}(3,4$, or 5 in)) which would encircle a child's arm comfortably was used. The 10-cm cuff was used for most children (2363), only three being measured with the $7.5-\mathrm{cm}$ cuff and 22 with the $12.5 \mathrm{~cm}$ cuff. The recorded pressures were adjusted to allow for the effect of cuff size, according to the recommendations of Long et al. ${ }^{10}$ For the $10-\mathrm{cm}$ cuff, $6 \mathrm{~mm} \mathrm{Hg}$ was subtracted from the observed systolic pressure and $2 \mathrm{~mm} \mathrm{Hg}$ from the diastolic pressure.

Blood was obtained one hour after a 50-g load of glucose by mouth. Plasma sugar was estimated by Hoffman's method ${ }^{11}$ and serum cholesterol was estimated by Huang's method. ${ }^{12}$ Serum insulin was measured by a modification of the method of Morgan and Lazerow. ${ }^{13}$ Weight was measured on a lever balance.

Correlation and regression analysis ${ }^{14}$ was used to determine the independent associations of blood pressure with other factors.

\section{Results}

Table I shows the simple correlations between systolic and diastolic blood pressure and possible associated variables. Relatively large coefficients were found for relations between the two blood pressures in each sex and between pressures and weight, but the coefficients between pressure and plasma sugar levels were also fairly large, particularly in boys. The correlations for insulin based on a maximum of 713 observations are given elsewhere. ${ }^{\circ}$

Weight and plasma sugar concentrations were not correlated with each other in either sex, indicating that their associations with blood pressure were independent of any effect of one on the other. To investigate these relations further, the mean values of systolic pressures were calculated at different levels of weight and plasma sugar for each sex. Table II shows the values for boys. Average pressure clearly increased with increasing plasma sugar at each weight level. These findings may possibly have been due to differences in age between the groups defined in the table so we divided the data according to three age groups. The relation between systolic blood pressure and plasma glucose was found in both sexes, at each age, and in each weight group (see fig). Some of the points plotted in the figure were derived from small numbers, but even so the relation seemed to be present throughout. All the slopes for boys and all but three for girls were significantly greater than zero as determined by correlation analysis $(P$ at least $<0.05)$. There were similar but less pronounced relations with diastolic blood pressure.

To assess the independent associations of blood pressure with age, height, and cholesterol concentrations as well as with plasma sugar levels and weight, a multilinear regression analysis was performed. All five variables were used simultaneously to estimate their total association with blood pressure-a measure of the association is given by the multiple correlation coefficient. The association between each
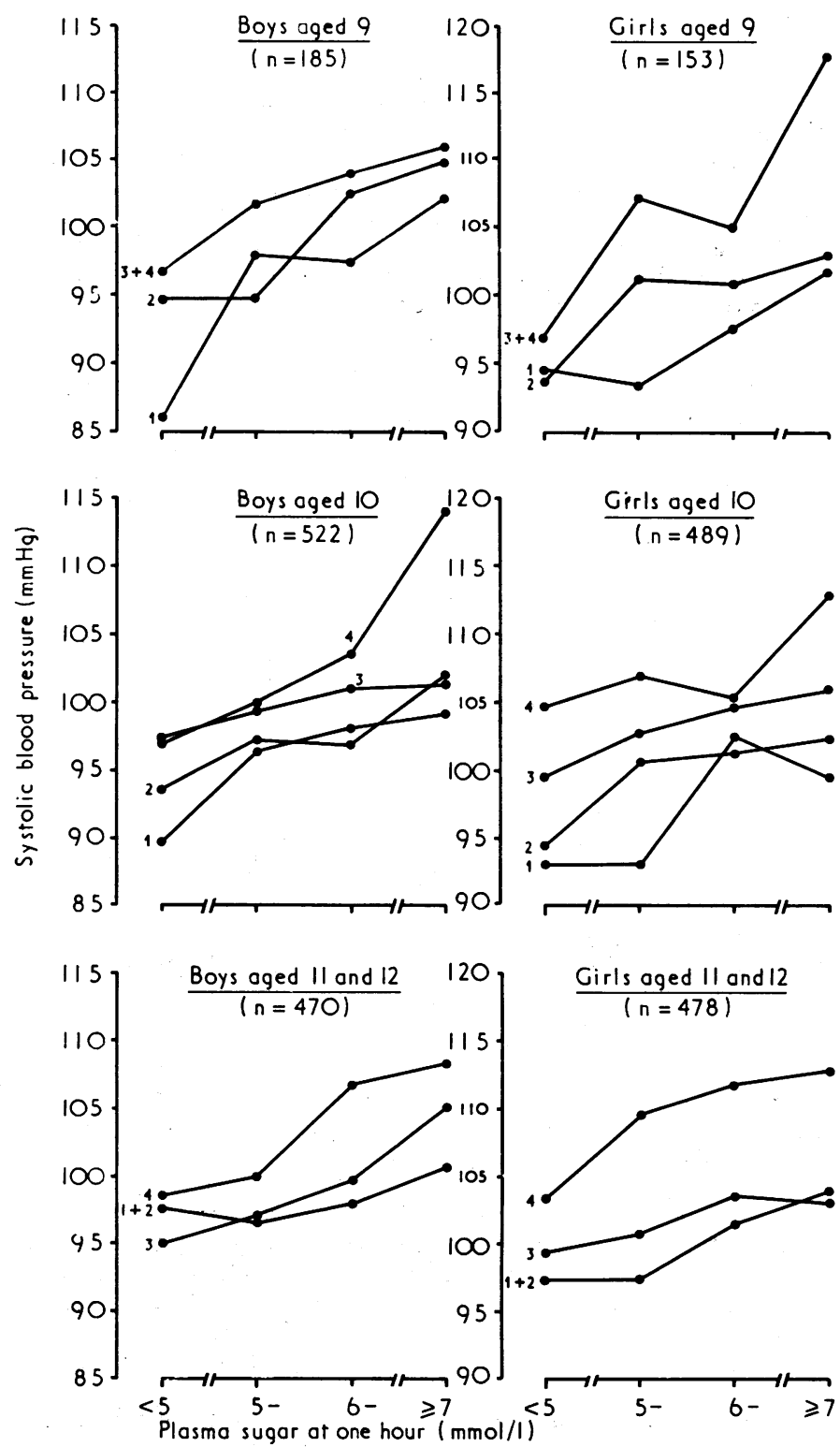

Mean values of systolic blood pressure according to plasma sugar concentrations, body weight, and age for boys and girls separately. Each line is for children in one body-weight group or, when numbers were small, two adjacent weight groups combined. The weight groups are coded: $1=<30$ kg. $2=30-34 \cdot 9 \mathrm{~kg} .3=35-39 \cdot 9 \mathrm{~kg} .4=\geqslant 40 \mathrm{~kg}$.

TABLE I-Correlation coefficients according to sex. (Maximum number of pairs of measurements used in calculation of each coefficient: Boys 1175-1214; Girls 1120-1174)

\begin{tabular}{|c|c|c|c|c|c|c|c|c|c|}
\hline & & Age & Cholesterol & Plasma sugar & Height & Weight & Diastolic BP & Systolic BP & \\
\hline Girls & $\begin{array}{l}\text { Age } \\
\left\{\begin{array}{l}\text { Cholesterol } \\
\text { Plasma sugar } \\
\text { Height } \\
\text { Weight } \\
\text { Diastolic BP } \\
\text { Systolic BP }\end{array}\right.\end{array}$ & $\begin{array}{l}0.05 \\
0.11^{*} \\
0.45^{*} \\
0.38^{*} \\
0.07 \\
0.14^{*}\end{array}$ & $\begin{array}{c}0.03 \\
-0.10^{*} \\
-0.04 \\
0.05 \\
0.03\end{array}$ & $\begin{array}{c}-0.01 \\
0.02 \\
0.15^{*} \\
0.22^{*}\end{array}$ & $\begin{array}{c}0.41^{*} \\
-0.06 \\
-0.01 \\
0.75^{*} \\
0.10^{*} \\
0.24^{*}\end{array}$ & $\begin{array}{c}0.34^{*} \\
0.00 \\
-0.01 \\
0.74^{*} \\
0.17^{*} \\
0.35^{*}\end{array}$ & $\begin{array}{c}-0.02 \\
0.08^{*} \\
0.15^{*} \\
0.04 \\
0.08^{*} \\
0.45^{*}\end{array}$ & $\left.\begin{array}{l}0.02 \\
0.08^{*} \\
0.30^{*} \\
0.11^{*} \\
0.21^{*} \\
0.47^{*}\end{array}\right\}$ & Boys \\
\hline
\end{tabular}

$* \mathrm{P}<0.01 . \quad \mathrm{BP}=$ Blood pressure. 
TABLE II-Mean systolic blood pressure ( $\mathrm{mm} \mathrm{Hg}$ ) for boys according to body weight and plasma sugar (number of observations in parentheses). Standard deviation for all groups $\approx 11.0 \mathrm{~mm} \mathrm{Hg}$

\begin{tabular}{|c|c|c|c|c|}
\hline \multirow{2}{*}{$\begin{array}{c}\text { Weight } \\
(\mathbf{k g})\end{array}$} & \multicolumn{4}{|c|}{ Plasma sugar $(\mathrm{mmol} / \mathrm{l})$} \\
\hline & $<5.0$ & $5 \cdot 0-5 \cdot 9$ & $6 \cdot 0-6.9$ & $\geqslant 7 \cdot 0$ \\
\hline $\begin{array}{c}<30 \\
30-34 \\
35-39 \\
\geqslant 40\end{array}$ & $\begin{array}{l}88.3(24) \\
94.9(66) \\
95.9(75) \\
98 \cdot 1(37)\end{array}$ & $\begin{array}{r}97 \cdot 7(42) \\
96 \cdot 3(122) \\
98 \cdot 2(122) \\
100 \cdot 4(63)\end{array}$ & $\begin{aligned} 97 \cdot 9(38) \\
98 \cdot 0(125) \\
100 \cdot 7(103) \\
105 \cdot 2(62)\end{aligned}$ & $\begin{array}{l}101 \cdot 4(33) \\
102 \cdot 0(110) \\
103 \cdot 3(104) \\
110 \cdot 2(50)\end{array}$ \\
\hline
\end{tabular}

Conversion: SI to traditional units-Glucose $1 \mathrm{mmol} / 1 \approx 18 \mathrm{mg} / 100 \mathrm{ml}$.

independent variable and blood pressure was tested after holding all the other independent variables constant. If one or more of the independent variables had a non-significant partial association with blood pressure they were removed and the analysis was repeated with the remaining variables. Table III gives the $P$ values for these partial associations. To verify the results of this backward elimination process, we repeated the analysis using stepwise regression. The same results as shown in table III were obtained.

TABLE III-Summary of regression analyses of blood pressure by sex

\begin{tabular}{|c|c|c|c|}
\hline Dependent variable & $\begin{array}{l}\text { Independent* } \\
\text { variables }\end{array}$ & $\mathrm{P}+$ & $\begin{array}{l}\text { Multiple } \\
\text { correlation } \\
\text { coefficient }\end{array}$ \\
\hline \multicolumn{4}{|c|}{ Boys $(n=1173)$} \\
\hline Systolic blood pressure & $\begin{array}{l}\text { Plasma sugar } \\
\text { Weight } \\
\text { Cholesterol } \\
\text { Height } \\
\text { Age }\end{array}$ & $\begin{array}{c}<0.0005 \\
<0.0005 \\
0.005 \\
<0.05 \\
0.05\end{array}$ & 0.385 \\
\hline Diastolic blood pressure & $\begin{array}{l}\text { Plasma sugar } \\
\text { Cholesterol } \\
\text { Weight } \\
\text { Age }\end{array}$ & $\begin{array}{l}<0.0005 \\
\approx 0.005 \\
<0.01 \\
<0.05\end{array}$ & $0 \cdot 192$ \\
\hline \multicolumn{4}{|c|}{ Girls $(n=1118)$} \\
\hline Systolic blood pressure & $\begin{array}{l}\text { Weight } \\
\text { Plasma sugar }\end{array}$ & $\begin{array}{l}<0.0005 \\
<0.0005\end{array}$ & 0.404 \\
\hline Diastolic blood pressure & $\begin{array}{l}\text { Weight } \\
\text { Plasma sugar }\end{array}$ & $\begin{array}{l}<0.0005 \\
<0.0005\end{array}$ & $0 \cdot 218$ \\
\hline
\end{tabular}

*In order of strength of association.

$P$ for association after effects of other variables have been allowed for.

For boys both blood pressures were most strongly associated with plasma sugar levels, followed by weight in the case of systolic pressure and cholesterol in the case of diastolic pressure. Some age effect, even over the short span of 9-12 years, was found after allowing for the effects of weight and height. For girls only two variables were significantly related to blood pressure: weight and plasma sugar. Both partial relations were highly significant. The strength of these relations was not reduced when the other variables were included in the regression, nor did the other variables taken singly or together help significantly to explain the variance of blood pressure. The multiple correlation coefficients were about twice as large for systolic as for diastolic pressure.

Because of the possibility of diurnal variation in the measurements and because children seen in the afternoon would have had lunch before their tests, the analysis was re-run on the four groups formed by sex and time of test (morning or afternoon). In every analysis weight and plasma sugar were the most important correlates of systolic blood pressure. Similar analysis of diastolic pressure showed plasma sugar as a significant correlate in all groups except girls measured in the afternoon.

The analysis was then re-run on the four groups to include the insulin values determined for 374 boys and 337 girls. ${ }^{9}$ For all groups except girls measured in the afternoon plasma sugar and weight were the variables most highly correlated with systolic blood pressure; the partial relations between systolic pressure and insulin, holding weight and plasma sugar constant, were not statistically significant. For the girls measured in the afternoon weight and insulin were the most important correlates.

In all the regression analyses height was included so that the relation of weight to blood pressure could be estimated after the removal of the effect of height. Although the inclusion of height usually altered the relation somewhat, the relative importance of plasma sugar and weight did not change from what is described above.

\section{Discussion}

We found that the relation between blood pressure and blood sugar levels after challenge, known to exist in non-diabetic adults, ${ }^{3-7}$ also exists in children. The variables related significantly to systolic and diastolic blood pressures in the Dutch girls were weight and plasma sugar; in boys they also included serum cholesterol levels, height, and age. This difference between the sexes in the significance of serum cholesterol concentrations has also been shown in an analysis of data for white adults who took part in the US national health survey. ${ }^{4}$ That survey showed that over the age range 18-79 years, age was the most important correlate for both sexes, followed by ponderal index (an index of weight adjusted for height) and, in third place, blood sugar concentrations. Serum cholesterol was significantly correlated with both blood pressures only in white men. The similarity of the results in these two studies suggests that at an early age the relation between the various risk factors for CHD differ between the sexes and have already taken on the patterns found in adults.

Nevertheless, despite the consistency of the findings in the studies in the more developed countries, one of us (CF) has obtained results from a rural adult population in Jamaica ${ }^{2}$ that did not follow the general pattern. Using the same methods of analysis as in this study and the US national health survey, systolic and diastolic pressures were found to be related in the two sexes to age and weight/height. In contrast to the results for Black men and women in the US study, however, neither of the pressures in men nor diastolic pressure in women were related to blood sugar levels one hour after challenge. Unlike the other studies, which were in populations where CHD is common, this survey was of a rural agricultural people with a low incidence of myocardial infarction. Although their serum cholesterol, blood sugar, and blood pressure levels were individually similar to those of people in more developed communities, the interrelationship were different-a result, we believe, of their own particular life-style, which in some way protects them from myocardial infarction.

Several factors that might link blood pressure and blood sugar levels have been suggested. 'These include age, sex, body weight, the use of oral diuretic agents in the treatment of hypertension (which in some people raises blood sugar levels), the use of oral contraceptives, and adrenocortical steroids. We have shown that age, sex, and body weight do not account for the association in children. Although we have no direct evidence, the use of diuretics, contraceptives, and steroids by children is extremely unlikely and, even if they were used, they would have to be taken by many children to account for the consistent findings in all the groups in fig 1 .

There are, nevertheless, several other explanations of the association between blood pressure and blood sugar in children which cannot be so easily dismissed. The association may represent a process that affects the structure of blood vessels, possibly the intimal lining of the major vessels or the basement membrane of the capillaries. Such lesions are seen in diabetics; the processes may also occur in "normal" people but at a level which, though undetectable by present methods, is, nevertheless, sufficient to cause the association we have described. Another possibility is that the associations may arise from the diet in some way: children may prefer to eat combinations of foods which raise both blood pressure, such as salt, and blood sugar, such as sweets. At present, this seems unlikely, at least with respect to salt. Recent evidence ${ }^{15}$ indicates that neither the need to add salt to food nor the taste threshold for salt is related to blood pressure in schoolchildren. It may of course simply be an artefact of the survey process, resulting from an unrecognised factor or factors such as catecholamines which raise both pressure and sugar. Against this, however, is the observation in two Chicago populations ${ }^{6}$ that plasma sugar and blood pressure were 
still associated after the effects of heart rate had been taken into account.

We cannot explain our finding satisfactorily, but through the investigation of children we have been able to exclude explanations which have relevance only to adults. If our findings are not simply an artefact of the examination procedure, then they suggest that in the more developed countries the relations seen in adults between four risk factors for CHD-blood pressure, adiposity, blood sugar, and serum cholesterol-are already evident in childhood.

We thank Professor A C Arntzenius and Professor J H de Haas for their help and encouragement in organising and carrying out this study; Dr B Grab of the World Health Organisation headquarters, Geneva, for providing the data tape; and $\mathrm{Mr}$ A Sadler for making the insulin determinations. We also thank Professor R M Acheson and Professor F H Epstein for their helpful comments on the manuscript. The Netherlands Heart Foundation provided financial support for the survey.

\section{References}

Epstein, F H, Circulation, 1967, 36, 609.

Florey, C du V, MD thesis, Cambridge, 1974

Epstein, F H, paper given at VIth World Congress of Cardiology, 1970.

4 Florey, C du V, and Acheson, R M, Vital Health Statitics, series II, No 34. Washington DC, US Government Printing Office, 1969.

${ }^{5}$ Stamler, J, et al, Bulletin of the New York Academy of Medicine, 1969, 45, 1306.

6 Stamler, J, et al, Circulation, 1974, 50, suppl 3, p 147.

7 Jarrett, J, and Keen, H, Complications of Diabetes, chap 5. London, Arnold, 1975.

${ }^{8}$ Uppal, S, MD thesis, Leiden, 1974.

9 Florey, C du V, Lowy, C, and Uppal, S, submitted for publication.

${ }^{10}$ Long, M, Dunlop, J R, and Holland, W W, Archives of Disease in Childhood, 1971, 46, 636.

${ }^{11}$ Hoffman, W S, fournal of Biological Chemistry, 1937, 120, 51.

12 Huang, T C, et al, Analytical Chemistry, 1961, 33, 1405.

${ }^{13}$ Morgan, C R, and Lazerow, A, Diabetes, 1963, 12, 115.

${ }^{14}$ Draper, N, and Smith, H, Appiied Regression Analysis. London, Wiley, 1966.

15 Lauer, R M, et al, Circulation, 1974, 50, Suppl 3, p 124

\title{
Growth, behaviour, and educational achievement of Jamaican children with sickle-cell trait
}

\author{
M T ASHCROFT, PATRICIA DESAI, S A RICHARDSON, G R SERJEANT
}

British Medical fournal, 1976, 1, 1371-1373

\section{Summary}

A longitudinal study of the mental and physical development of 200 children with normal haemoglobin and 21 with the sickle-cell trait was carried out in a small rural community in Jamaica. At about 2 and 10 years of age heights and weights showed no significant differences. At about 10 years of age classroom behaviour, sociability, and educational achievement were similar. The results suggest that the sickle-cell trait does not affect growth and mental development.

\section{Introduction}

In homozygous sickle-cell disease some $80-97 \%$ of the total haemoglobin is sickle haemoglobin ( $\mathrm{Hb} \mathrm{S}$ ), and these high levels are associated with well recognised pathophysiological sequelae. Heterozygous sickle-cell trait, however, is characterised by about $20-50 \% \mathrm{Hb} \mathrm{S}$ and is essentially benign, though in this disease generalised or localised anoxia may occasionally produce conditions such as splenic infarction ${ }^{1}$ or haematuria. ${ }^{2}$ Vascular occlusive episodes have also been attributed to the sickle-cell trait but the causal role of $\mathrm{Hb} \mathrm{S}$ has not been confirmed. ${ }^{3}$

A report from the USA ${ }^{4}$ suggested that some aspects of the physical and mental development of children with the sickle-cell

\footnotetext{
Medical Research Council Laboratories (Jamaica), University of the West Indies, Kingston 7, Jamaica WI

M T ASHCROFT, DSC, MRCP, epidemiologist

PATRICIA DESAI, BA, statistician

G R SERJEANT, MD, MRCP, director
}

Department of Paediatrics, Albert Einstein College of Medicine, Yeshiva University, Bronx, New York

S A RICHARDSON, PHD, professor of paediatrics and community health trait may be impaired. In view of the far-reaching implications we have compared the growth, behaviour, and educational achievement of Jamaican children with the trait and with normal haemoglobin.

\section{Subjects and methods}

All the children had been included in early childhood studies of growth and development in Lawrence Tavern, a rural area of Jamaica. ${ }^{5} 6$ The geographically defined district is about $30 \mathrm{sq} \mathrm{km}$ and has a total population of 8000 , mainly of African origin. The predominant occupation is subsistence farming, and the people are, in general, poor, although few are destitute. The pattern of disease is like that of a temperate rather than tropical country. Parasitic infections such as malaria, schistosomiasis, and filariasis are absent, although intestinal helminthiasis is common. Mortality rates in the first two years of life are high but subsequently fall to about the same as in the United Kingdom.

In 1974,247 children aged $9-11 \frac{1}{2}$ years who were still living in the area were available for further investigations. A test of reading, spelling, and arithmetic (the Wide Range Achievement Test) ${ }^{7}$ was given to each child individually. The children, with the exception of four who were not enrolled at any school, were pupils at nine local schools. Teachers and fieldworkers completed questionnaires, from which indices of classroom behaviour and sociability were derived. School attendance was obtained for the previous two terms from school registers. Medical histories were taken and clinical examinations performed if deemed necessary. Socioeconomic status, based on housing, furnishing, income, and employment, was assessed on a four-point scale after a home visit by a field worker. Family structure, which may also influence educational achievement and behaviour, was recorded. Heights and weights at about 2 years of age were obtained from the children's records and were measured again in 1974. Each measurement was expressed as a standard score, which is the number of standard deviations by which the measurement differs from the mean of a reference population of the same age and $\operatorname{sex}^{5} 8$

In 1975 venous blood was obtained from 231 (94\%) of the 247 children and examined by haemoglobin electrophoresis on cellulose acetate and agar gel. The presence of $\mathrm{Hb} \mathrm{S}$ was confirmed by metabisulphite sickle tests. The study was "double blind," since genotypes were determined by staff unaware of the results of other assessments. 